\title{
Measuring and modelling of process forces during tapping using single tooth analogy process
}

\author{
F. Geßner ${ }^{1} \cdot$ M. Weigold ${ }^{1}$ (I) $\cdot$ E. Abele ${ }^{1}$
}

Received: 7 September 2020 / Accepted: 16 November 2020 / Published online: 2 December 2020

(c) The Author(s) 2020

\begin{abstract}
For machining internal threads, tapping is a commonly used process. However, due to the complex geometry of the tapping tool, each tooth has a unique geometry resulting in individual forces. Since the forces act synchronously during the process, they partly compensate each other. However, since resulting forces in tapping can cause undesired deflection of the tool which can lead to threads that are not true to gauge or tool breakage, the knowledge of the forces is crucial. To predict the occurring forces on each tooth, different modelling approaches can be used. An approach based on the chip load-cutting force relationship is the mechanistic modelling. Therefore, a suitable force model is of central importance. An empirical force model can be established using an analogy process. Within this work a single tooth analogy process is presented to measure the forces of each tooth separately. By means of a geometrical analysis of the real tool, the chip sizes, such as the cross-section area of the undeformed chip are calculated. Merging the measured process forces from the analogy process and the actual chip sizes, an empirical force model is set up using multivariate regression. The model is validated by implementing it in an existing framework and comparing the results to experimental data.
\end{abstract}

Keywords Tapping $\cdot$ Modelling $\cdot$ Force $\cdot$ Torque $\cdot$ Analogy process

\section{Introduction}

Threaded joints are widely used as detachable connecting elements. In addition to thread milling and thread forming, tapping is a common process for the machining of internal threads. In tapping, material is removed from the bore wall in a continuous cutting process, whereby the thread is cut successively by the tooth of the tap. Since the process is located at the end of the value-added chain, tool failure is associated with expensive rework or component scrap [1]. The industry is therefore constantly striving to increase process stability to reduce failures and the need for human intervention [2]. To achieve this, it is necessary to increase the understanding of the tapping process. This includes especially the forces acting during the process. Due to the

M. Weigold

m.weigold@ptw.tu-darmstadt.de

F. Geßner

f.gessner@ptw.tu-darmstadt.de

1 Institute of Production Management, Technology and Machine Tools (PTW), Otto-Berndt-Str. 2, 64287 Darmstadt, Germany individual geometry of each tooth the load distribution on the tap is not even, resulting in radial forces (see Fig. 1) that can lead to a lateral deflection of the tool. However, these forces act synchronously and are partly compensated by the complex contact conditions between tool and component, which means that they cannot be measured directly in the real tapping process. Therefore, an analogy process is necessary to measure the process forces on each tooth separately. The measured forces can then be fed into process models in order to increase process stability by supporting the knowledge-based tool and process design.

\section{State of the art}

A widely used method for cutting force prediction is mechanistic modelling. The mechanistic approach is based on the chip load-cutting force relationship according to Koenigsberger and Sabberwal [3]. Therefore, the process forces during machining can be calculated as the product of the specific process forces and the cross-section area of the undeformed chip. Kapoor et al. [4] describe the general structure of a dynamic model for various kinds of cutting 

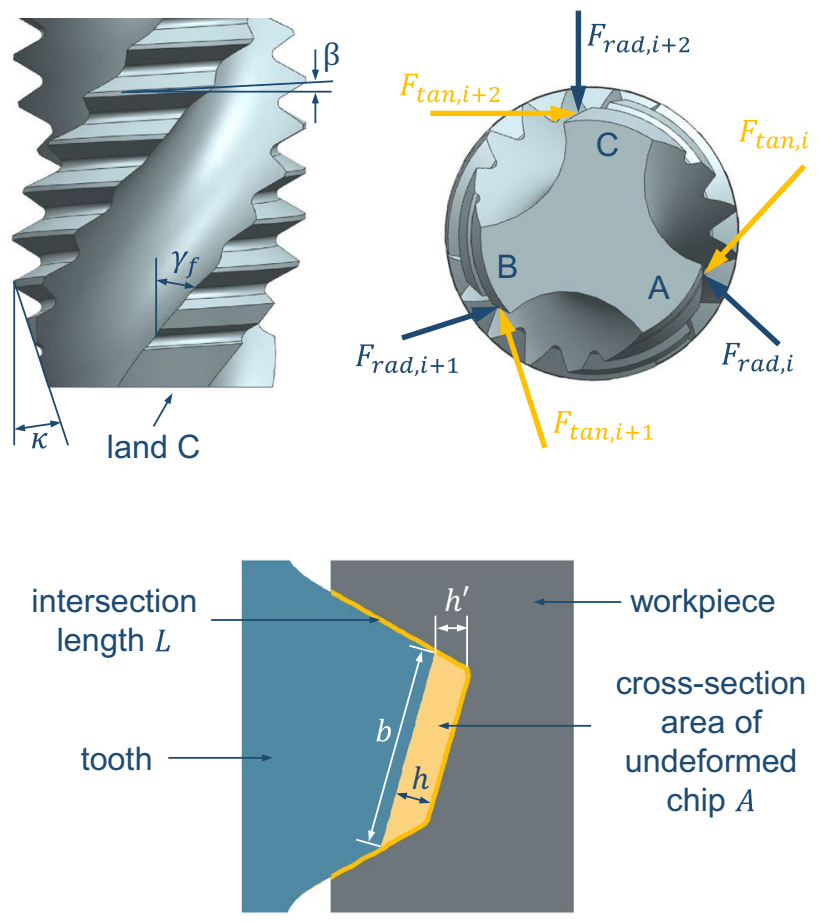

Fig. 1 Forces on three exemplary teeth of a tapping tool and toothworkpiece intersection

processes with geometrically defined cutting edge according to the mechanistic framework. Therein several submodels are combined to a closed loop model. Using a workpiececutter model and a chip load model the local time-dependent cross-section area of the undeformed chip is calculated. In the cutting force model, this is converted into the chip induced process forces. The deflection of tool and workpiece is calculated based on the acting process forces and fed back via a feedback model. A review on mechanistic modelling is provided by Ehmann [5].

For tapping process modelling, this approach is commonly used to estimate the prevailing forces. It is particularly suitable for describing the effects of uncertainty like axis misalignment, tool runout and synchronization errors on the tapping process [6]. A mechanistic model for tapping with emphasis on uncertainty is presented by Dogra et al. [1]. The authors describe the geometrical mapping of axis misalignment and tap runout in the model. In addition, they investigate deviations in the bore geometry and show the influences on the torque. In a further work, the authors add a contact stress model to explain the phenomenon of feed errors in tapping [7]. A model-based investigation on radial forces in tapping is presented by Mezentsev et al. [8]. They use a mechanistic model to study the effects of axis misalignment, tap runout and tooth breakage on the resulting radial forces. Cao and Sutherland [9] investigate the load characteristics in tapping using the mechanistic approach.
The presented model predicts torque and axial force arising from chip formation and friction between the tooth flanks and the workpiece for straight fluted taps.

Based on Armarego's unified generalized mechanics of cutting approach [10, 11] Puzović and Kokotović [12] develop a model that provides deeper insight into the effects of cutting edge breakage and tool wear. To represent the complex geometry of the tap, the cutting edges are divided into elementary cutting segments for which classic oblique cutting is assumed. A further use of this approach can be found in the work of Chen and Smith [13] for modelling of straight flute machine tapping. A model-based study on feed errors in tapping is presented by Wan et al. [14]. To predict the effects of the minor cutting edges of straight flute taps Popović et al. [15] present a model for tapping torque and force. The geometry of the mayor and minor cutting edges is therefore extracted from a parametric CAD model of the tap.

All described models base on the chip load-cutting force relationship using specific process forces. Taking the mechanical properties of the component and the tool material into account, the specific process forces can be determined by numerical calculation or by machining tests, for example orthogonal cutting tests in turning [16]. Empirical force models based on orthogonal cutting analogy processes can be found in $[9,12]$. Another method is presented by Dogra et al. [1] using drilling tests to calibrate a tapping force model.

A numerical approach for torque and force prediction in tapping processes, that has made huge progress over the last years, is the finite element method (FEM). However, since cutting simulation using FE-modelling is a challenging task and requires plenty of computing time, Oezkaya and Biermann use a segmented workpiece model to significantly reduce the simulation time for a single thread to $170 \mathrm{~h}$ [17]. To further reduce the high computing time the authors develop a geometrical torque prediction method based on the simulated forces to determine the relative torque for different tapping tools and diameters [18].

An experimental approach to directly measure the forces of parts of the cutting section of the tapping tool is presented in [19]. To divide and separately measure the forces acting synchronously during the process, multiple taps with ground back teeth are used. Each tap having one more set of three teeth (also referred to as a fillet) than the previous one. This is intended to provide support for the tool, prevent uneven axial load and give closer insights in the tangential forces. A similar approach is used to study the temperature during tapping [20].

Concerning the geometry of the cross-section of the undeformed chip in tapping process models, the approximation as a trapezoid is widely used. Puzović and Kokotović describe the cross-section of the undeformed chip using a regular trapezoid, the height of which is calculated from 
the difference in the depths of engagement of two successive teeth [12]. Mezentsev et al. and Dogra et al. specify the cross-section of the undeformed chip over the four corner points $[1,8]$. The outer vertices of the trapezoid are defined by the current tooth and the inner ones by the previous tooth. The tool-workpiece interaction can be described as a boolean operation between tooth and workpiece. This approach is also used in [6], where both tooth and chip are described as polygons and therefore no predefined number of corners is required.

\section{Research objective}

Various studies have shown the application of force and torque modelling approaches in tapping. However, they mainly base on idealistic tool geometries and hence give idealistic cross-sections of the undeformed chip, which are the basis for the process force prediction. Experimental approaches to measure the radial forces on each tooth of a tapping tool separately were not presented so far.

The aim of this article is to evaluate and model the process forces occurring on each individual tooth of a tap on an empirical basis. Therefore, an analogy process is developed which represents the tapping process as accurately as possible, but only has one tooth in engagement at a time. This results in the process forces of each individual tooth. In addition, the surface of the tapping tool used in the experiments is optically measured and analysed to extract the real tooth geometry and the resulting cross-section of the undeformed chip. Knowing the real process forces on each tooth and the respective chip sizes, an empirical model to predict tapping torque and radial forces is set up and calibrated using a multivariate regression with least squares method. For validation the model is combined with an existing tool workpiece intersection model [6] and compared to experimentally measured data.

\section{Methodology}

\subsection{Evaluation of tooth geometry}

The geometry of a tap is basically determined by the thread to be produced. The sizes for describing the tap are given in DIN 2197 [21], but these are not sufficient to describe the tap unambiguously. Sizes such as the position and size of the first tooth that have a decisive influence on the chip cross-section of each individual tooth, are not specified in DIN 2197. The definition of these sizes is left to the tool manufacturers [22]. In addition, manufacturing variations may lead to deviations in the geometry. Therefore, when comparing simulated and experimental results, it is necessary to refer to the real geometry of a tap and evaluate the cross-sections of the undeformed chip for each tooth.

To evaluate the real tool geometry (Fig. 2a), the surface of the three fluted M8x1.25 tap, according to DIN 371 [23], used in the experiments is recorded with the optical surface measuring device Alicona Infinite Focus G5 of Alicona Imaging $\mathrm{GmbH}$ with connected rotatory unit. The digital representation of the tool surface (Fig. 2b) can be exported in standard tessellation language (stl). In this file format, the tool surface is represented by numerous faces $S$, each specified by three vertices $V$. For the given tool, there are 1,013,833 faces and 508,018 vertices with a vertical and lateral resolution of $0.100 \mu \mathrm{m}$ and $5.918 \mu \mathrm{m}$ respectively. The selected resolution represents a good compromise between manageable file size and accuracy. In the following, the vertices are transformed into cylindrical coordinates with the origin in the tool centre point. a)

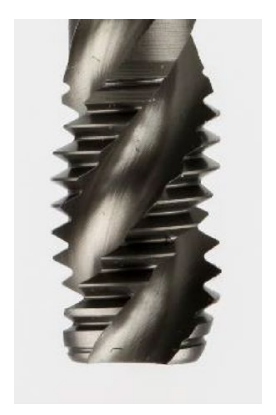

b)

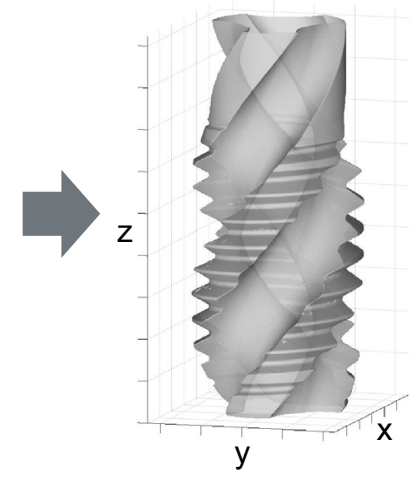

c)

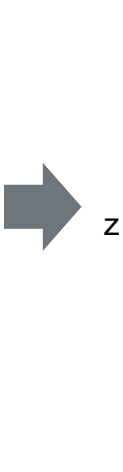

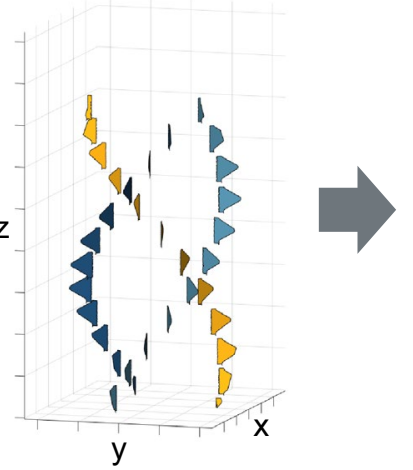

d)

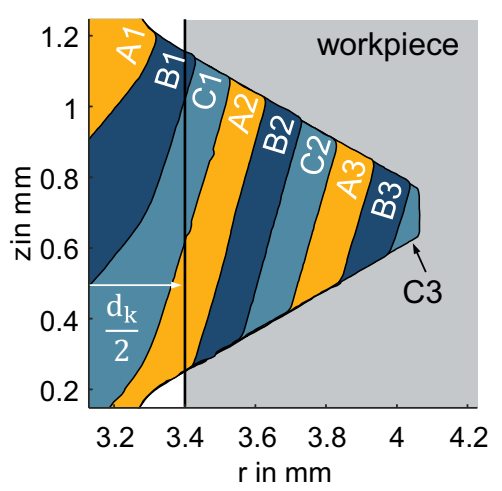

Fig. 2 Steps in the evaluation of the tool geometry: a real tool, $\mathbf{b}$ digital representation of the tool surface, $\mathbf{c} 2 \mathrm{D}$ element set model and $\mathbf{d}$ tooth overlap 
Thus, each vertex position is defined by its distance to the tool centerline $r$, the direction angle $\varphi$ and the height $z$. To extract plane elements representing the individual teeth, the following procedure is applied for each tooth $T_{i}$, with index $i$ as consecutive numbering of the teeth.

For the analysis of the tooth, the region of interest (ROI) is specified including only relevant faces $S_{n_{i}}$ and their vertices $V_{j_{i}}$, with the indices $n_{i}$ and $j_{i}$ being counting variables for the faces and vertices of the tooth $T_{i}$ respectively. The focus is mainly on the rake face and the cutting edge of the tooth. To generate a two-dimensional representation of the tooth $T_{i}$, the tooth reference plane $E_{T_{i}}$, containing the centre axis of the tool and the tooth tip, is defined. This corresponds to the tool reference plane described in DIN 6581 [24]. Each vertex $V_{j_{i}}$ in the defined ROI is then projected to a vertex $V_{j_{i}}^{\prime}$ within the plane $E_{T_{i}}$. To follow the tooth trajectory in the cutting process, the pitch $P$ of the thread is considered in the projection. Thus, it is possible to determine the orthogonal cross-section of the tooth as it passes through the plane under ideal conditions.

$V_{j_{i}}^{\prime}=\left(\begin{array}{c}r_{j_{i}} \\ \varphi_{j_{i}} \\ z_{j_{i}}\end{array}\right)-\left(\begin{array}{c}0 \\ \varphi_{j_{i}}-\varphi_{T_{i}} \\ \left(\varphi_{j_{i}}-\varphi_{T_{i}}\right)^{\prime} \cdot \frac{P}{2 \cdot \pi}\end{array}\right)$

Here $r_{j_{i}}, \varphi_{j_{i}}$ and $z_{j_{i}}$ are the respective coordinates of point $V_{j_{i}}$ and $\varphi_{T_{i}}$ is the position angle of the plane $E_{T_{i}}$. Due to the projection of the vertices $V_{j_{i}}^{\prime}$ the faces $S_{n_{i}}^{\prime}$ lie within the plane $E_{T_{i}}$. The polygon $T_{i}$ representing the tooth can be described as the union of all $m_{i}$ projected faces $S_{n_{i}}^{\prime}$

$T_{i}=\bigcup_{n_{i}=1}^{m_{i}} S_{n_{i}}^{\prime}$

By combining the individual plane elements of each tooth, the tool can be mapped as an 2D element set model (Fig. 2c), as described by Zabel [25].

Based on the extracted geometry of each tooth $T_{i}$, the cross-section area of the undeformed chip $A_{i}$ can be calculated by a boolean operation of the workpiece $W$ and the two consecutive teeth $T_{i}$ and $T_{i-1}$, assuming that the teeth are projected to the same reference plane, for example the $\mathrm{x}-\mathrm{z}$-plane, considering the pitch of the tool, as shown in Fig. 2d). The absolute value of $A_{i}$ is then calculated using Gauss's area formula.

$A_{i}=\left|W \cap\left(T_{i}-T_{i-1}\right)\right|$

According to [26], the undeformed chip thickness $h$ results from the radial depth of cut $h^{\prime}$ tilted by the chamfer angle $\kappa$, as shown in Fig. 1. The calculation of the undeformed chip width $b$ is performed analogously. $h=h^{\prime} \cdot \cos (\kappa)$

$b=\frac{b^{\prime}}{\cos (\kappa)}$

The intersection length $L$ (as shown in Fig. 1) can be described as the length of the boundary $\Gamma_{i}$ of the tooth $T_{i}$ within the workpiece $W$ and can be used to describe edge forces in tapping [12].

$L_{i}=\left|\Gamma_{i} \cap W\right|$

The chip sizes assuming a pilot bore diameter of $d_{k}=6.8 \mathrm{~mm}$ are shown in Table 1. Referring to Ahn [27], the teeth are clearly assigned by a combination of a letter for the land of the tap and a number for the tooth on the respective land.

\subsection{Single tooth analogy process}

In order to determine the individual force components on each tooth experimentally, a modified plunge turning test is used, as shown in Fig. 3. The kinematic reversal with rotating component and stationary tool allows to measure forces in the stationary tool coordinate system. By switching from machining an internal thread to an external groove, the engagement of a single tooth in the component material can be realized. To reduce uncertainty in form of lateral deflection due to the single sided forces, the tap is clamped in a special holding device using a half thread supporting the teeth on the opposite side of the tooth engaged (see Fig. 3). Thus, a stationary chip removal with constant cross-section area of the undeformed chip can be guaranteed during the cut. In addition to lateral support, the half thread also serves for positioning in z-direction when positioning the tap on the

Table 1 Geometrically evaluated chip sizes of the measured M8x1.25 tap assuming a pilot bore diameter of $d_{k}=6.8 \mathrm{~mm}$, as shown in Fig. 2d)

\begin{tabular}{lllll}
\hline Tooth & $A\left(\mathrm{~mm}^{2}\right)$ & $h(\mathrm{~mm})$ & $b(\mathrm{~mm})$ & $L(\mathrm{~mm})$ \\
\hline A1 & 0 & 0 & 0 & 0 \\
B1 & 0.002 & 0.038 & 0.129 & 0.155 \\
C1 & 0.035 & 0.116 & 0.488 & 0.633 \\
A2 & 0.076 & 0.124 & 0.825 & 1.072 \\
B2 & 0.079 & 0.121 & 0.771 & 1.209 \\
C2 & 0.063 & 0.116 & 0.638 & 1.333 \\
A3 & 0.050 & 0.121 & 0.497 & 1.477 \\
B3 & 0.032 & 0.115 & 0.363 & 1.612 \\
C3 & 0.008 & 0.062 & 0.196 & 1.659 \\
A4 & 0 & 0 & 0 & 1.665 \\
B4 & 0 & 0 & 0 & 1.666 \\
C4 & 0 & 0 & 0 & 1.660 \\
\hline
\end{tabular}



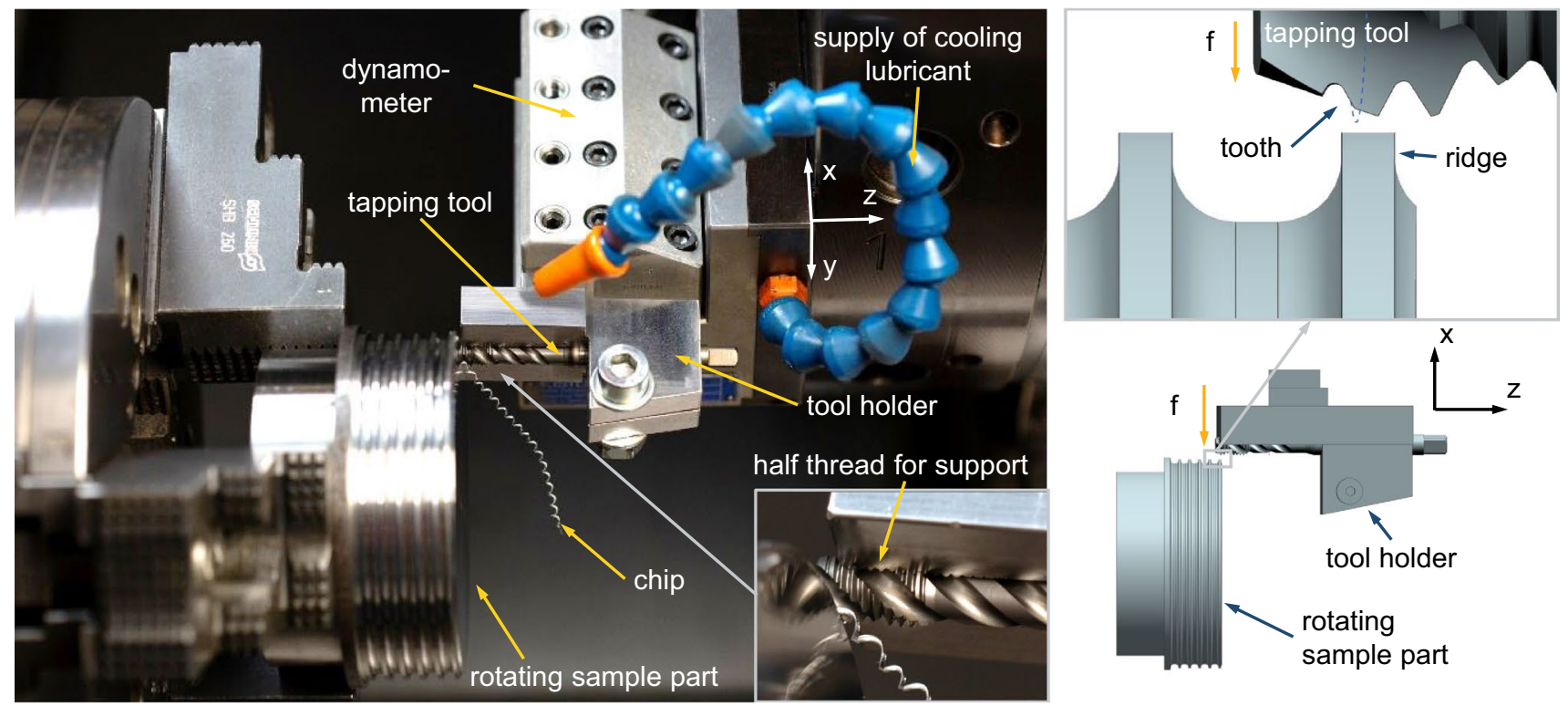

Fig. 3 Experimental setup of the single tooth analogy process

next tooth. For exact positioning, therefore, only the angle of rotation of the tap needs to be adjusted. This is done using a setting gauge which positions the centre of the tooth perpendicular to the component surface. The set position after the adjustment can be seen in Fig. 3.

Essential for the force measurement of each individual tooth is that there is a temporally separated tooth engagement. Some papers therefore describe analogous processes in which parts of the tool are ground back [28-30]. This however results in a destruction of the tool, making further tests with the exact tool impossible. In this work a nondestructive method is presented, where the tool stays intact and the separated engagement of the tooth is realized by modification of the workpiece geometry. For this purpose, circumferential ridges are applied to the test component, into which the thread is successively cut. To cut a circumferential groove in the ridge face, the pitch $P$ of the tap is compensated by tilting the tool relative to the rotation axis of the part. The required adjustment corresponds to the pitch angle $\beta$ and can be calculated according to DIN 13-28 [31] as follows:

$\beta=\tan ^{-1}\left(\frac{P}{d_{2} \cdot \pi}\right)=\tan ^{-1}\left(\frac{1.25 \mathrm{~mm}}{7.188 \mathrm{~mm} \cdot \pi}\right) \approx 3.17^{\circ}$

For force measurement during the cut, the tool is infeed to a specified $x$-position while the component is rotating. The workpiece rotation, the $\mathrm{x}$-position of the tool and the measured forces for one tooth of the tap are shown in Fig. 4. The $\mathrm{x}$-position is chosen so that the distance between the ridge surface and the tool center axis is half the diameter of the pilot bore $d_{k}$. In this position, the tap cuts a constant chip over the entire circumference of the workpiece, generating the forces shown in Fig. 4. To ensure complete chip removal over one revolution the total dwell time after infeed is set to 1.5 revolutions. The tool is then moved away in positive $\mathrm{x}$-direction. After the measurement procedure for one tooth is finished, the tap is unclamped, turned to the next tooth, adjusted and reclamped. As a result, all teeth of the tap cut in the same groove successively, in analogy to the real tapping process. The procedure is repeated for the first four teeth of each land.

For the experiments a lathe DMG CTX 800 beta is used. The process forces are recorded by a Kistler dynamometer Type $9121 \mathrm{~B}$ and evaluated in Matlab. 42CrMo4 is used as workpiece material. The tool used is a M8 machine tap. It has a pitch of $1.25 \mathrm{~mm}$, a helix angle $\gamma_{f}$ of $45^{\circ}$ and chamfer form $\mathrm{C}$ according to DIN 2197 [21]. The tolerance class is ISO $2 / 6 \mathrm{H}$. The tap is made of HSS-E and has a GLT- 1 coating. An emulsion with $8.8 \%$ oil content is used as cooling lubricant, which is fed directly to the cutting point via a nozzle (see Fig. 3). The tests are carried out at cutting speeds of 5,15 and $25 \mathrm{~m} / \mathrm{min}$, each with three repetitions. To ensure that the results are not influenced by manufacturing uncertainty, the same tool is used for all experiments (Table 2).

The tangential, radial and axial forces relative to the tool can be calculated by transforming the measured force signals into the tool coordinate system:

$F_{\text {tan }}=F_{y} \cdot \sin (\beta)+F_{z} \cdot \cos (\beta)$ 

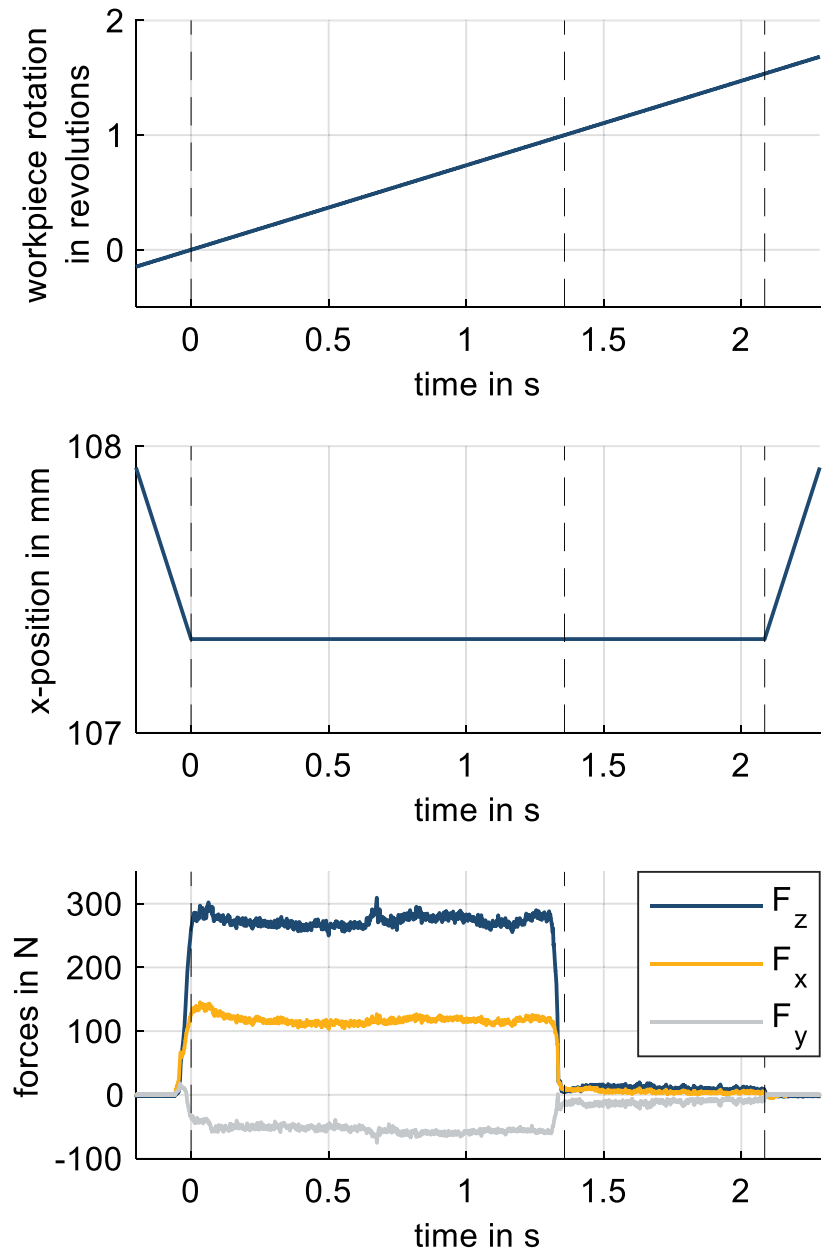

Fig. 4 Procedure of force measurement on a single tooth for $v_{c}=15 \mathrm{~m} / \mathrm{min}$ : Workpiece rotation, x-position of the tool and the measured forces during the analogy process
$F_{\text {rad }}=F_{x}$

$F_{a x}=F_{y} \cdot \cos (\beta)-F_{z} \cdot \sin (\beta)$

\section{Results and discussion}

\subsection{Geometry of the tool and the undeformed chips}

Analysing the extracted tooth elements shows, that the tip of the first tooth of the tap, referred to as A1, has a radius of $3.319 \mathrm{~mm}$. With the pilot bore radius $d_{k} / 2=3.4 \mathrm{~mm}$, as recommended in DIN 336 [32], the tooth A1 does not remove a chip. The first tooth with chip removal is therefore tooth B1. The largest cross-section area of the undeformed chip is measured for tooth B2, since this is the first tooth of the tool, which no longer increases the width of the thread, but only the depth. This also reflects in a lower increase of the contact length. The cross-section areas of the undeformed chip for the following teeth then continue to decrease, because of the thread flanks converging in an $60^{\circ}$ angle. The last tooth to cut material from the thread is $\mathrm{C} 3$. All the following teeth do not perform any chip removal. The undeformed chip width shows a largely similar distribution (see Fig. 5). However, it should be noted that due to the trapezoidal chip shape of the crosssection of the undeformed chip in tapping, the cross-section area is not equal to the product of the thickness and width of the undeformed chip.

$A \neq h \cdot b$

Except for the first and last cutting tooth engaged, the measured undeformed chip thickness $h$ is largely constant over the cutting teeth at approximately $0.12 \mathrm{~mm}$. Since the tool has a constant lead angle $\kappa$, this can be idealised calculated by the following formula, where $Z$ represents the number
Table 2 Mean force values during stationary chip removal on the single teeth based on experimental results (in $\mathrm{N}$ )

\begin{tabular}{|c|c|c|c|c|c|c|c|c|c|}
\hline \multirow[t]{2}{*}{ Tooth } & \multicolumn{3}{|c|}{$v_{c}=5 \mathrm{~m} / \mathrm{min}$} & \multicolumn{3}{|c|}{$v_{c}=15 \mathrm{~m} / \mathrm{min}$} & \multicolumn{3}{|c|}{$v_{c}=25 \mathrm{~m} / \mathrm{min}$} \\
\hline & $F_{\text {tan }}$ & $F_{\text {rad }}$ & $F_{a x}$ & $F_{\text {tan }}$ & $F_{\text {rad }}$ & $F_{a x}$ & $F_{\text {tan }}$ & $F_{\text {rad }}$ & $F_{a x}$ \\
\hline A1 & 0.00 & 0.00 & 0.00 & 0.00 & 0.00 & 0.00 & 0.00 & 0.00 & 0.00 \\
\hline B1 & 7.86 & 7.74 & -2.49 & 10.46 & 5.79 & -3.17 & 11.67 & 6.31 & -3.89 \\
\hline $\mathrm{C} 1$ & 150.56 & 70.60 & -39.29 & 125.76 & 58.26 & -42.34 & 110.71 & 51.82 & -36.77 \\
\hline A2 & 296.12 & 145.61 & -59.50 & 268.38 & 135.43 & -63.30 & 260.34 & 132.31 & -62.84 \\
\hline B2 & 304.50 & 163.13 & -32.77 & 289.63 & 146.44 & -49.18 & 283.32 & 154.63 & -31.84 \\
\hline $\mathrm{C} 2$ & 251.72 & 137.77 & -13.82 & 231.72 & 126.56 & -31.12 & 233.74 & 128.67 & -23.65 \\
\hline A3 & 157.17 & 75.36 & -29.05 & 176.13 & 88.90 & -34.52 & 159.94 & 79.28 & -33.09 \\
\hline B3 & 145.00 & 86.06 & 42.59 & 113.59 & 76.76 & 16.97 & 115.36 & 71.96 & 6.69 \\
\hline $\mathrm{C} 3$ & 66.12 & 57.09 & 35.54 & 46.26 & 38.50 & 11.86 & 33.57 & 20.38 & 3.23 \\
\hline A4 & 16.93 & 46.62 & 37.20 & 14.96 & 34.90 & 13.08 & 15.29 & 23.84 & 1.28 \\
\hline B4 & 18.22 & 48.53 & 43.30 & 15.60 & 38.98 & 19.41 & 25.47 & 34.39 & -2.27 \\
\hline $\mathrm{C} 4$ & 17.38 & 51.19 & 36.13 & 9.60 & 39.92 & 17.09 & 8.22 & 20.13 & 6.71 \\
\hline
\end{tabular}




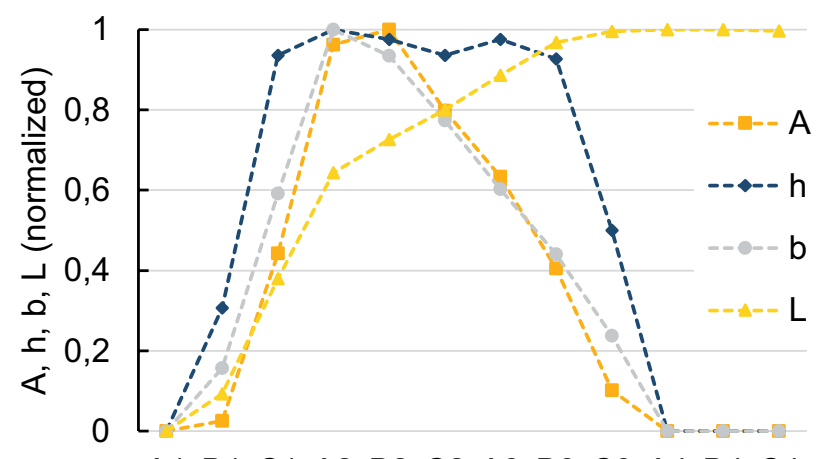

A1 B1 C1 A2 B2 C2 A3 B3 C3 A4 B4 C4

Fig. 5 Chip sizes of the undeformed chip: cross-section area $A$, chip thickness $h$, chip width $b$ and intersection length $L$, normalized to their maximum values

of flutes of the tool, $P$ is the pitch and $\gamma_{f}$ is the angle of the helical flute, as shown in Fig. 2a).

$h=\frac{P \cdot \sin \left(\gamma_{f}\right)}{Z}$

\subsection{Process forces on the single tooth}

The forces on each tooth of the tap are shown in Fig. 6. As described in Sect. 5.1, with the analogy process being set to map a pilot bore diameter of $d_{k}=6.8 \mathrm{~mm}$, there is no interaction between tooth $\mathrm{A} 1$ and the component during the tests leading to no measurable process forces. For teeth B1 to $\mathrm{C} 3$ in the cutting section of the tap, the tangential forces recorded are proportional to the measured cross-section area of the undeformed chip. Here, a slight influence of the cutting speed can be observed, which leads to a reduction of the tangential force with increasing cutting speed. For teeth A4-C4 in the guiding section of the tap, no further material is cut out of the thread, but forces can still be measured. It is evident that these are friction forces due to the contact between the tooth and the flanks of the thread.

The proportionality to the cross-section area of the undeformed chip can also be seen in the radial forces in the cutting section. The magnitude of these forces is about $50 \%$ less than the tangential forces (see Fig. 6). However, for the first teeth of the guiding section (A4-C4), the passive forces measured are considerably larger. Furthermore, these contact forces show a strong influence of cutting speed. It can be noted that for equal cutting speeds the forces of teeth A4-C4 are nearly constant. In the real process it can therefore be assumed that they compensate each other to a large extent and lead to a lateral stabilization of the tool.
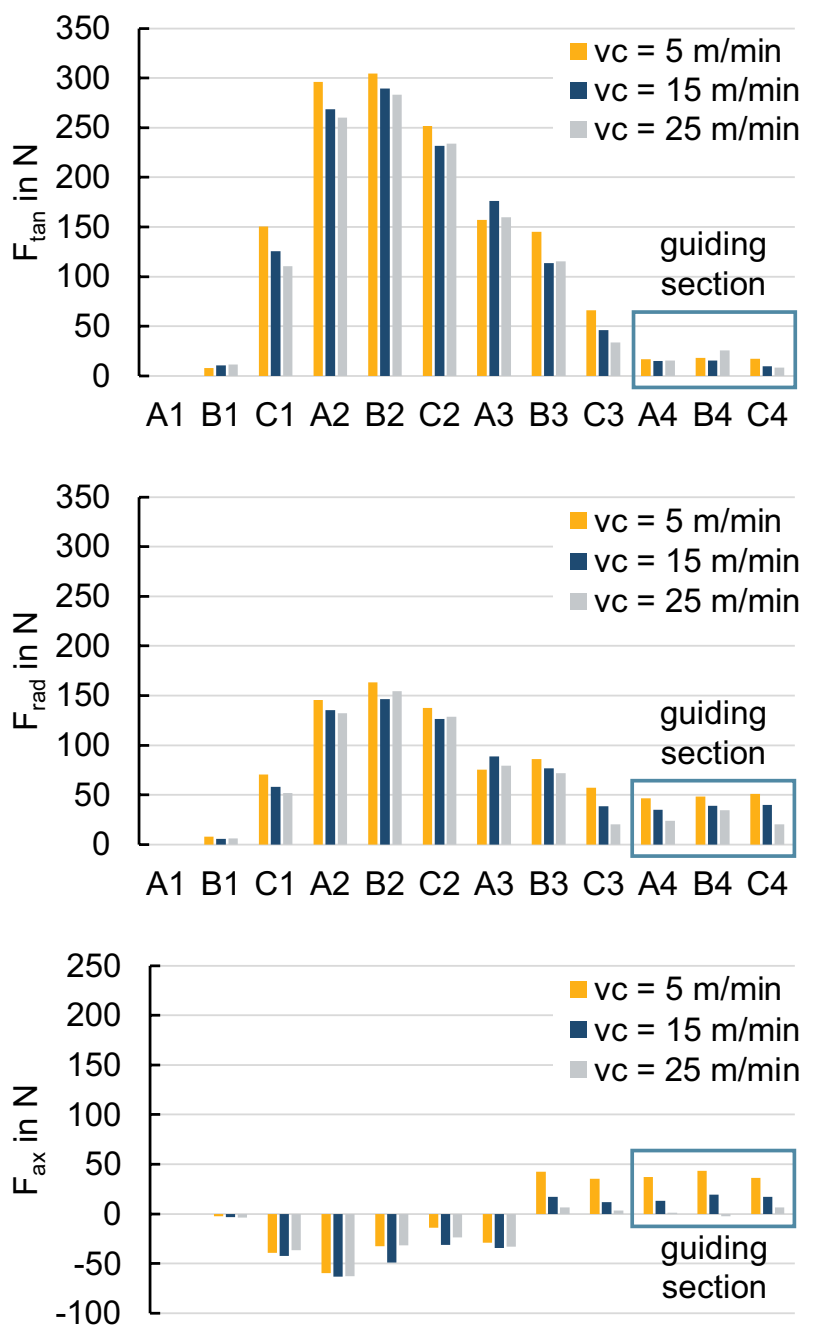

A1 B1 C1 A2 B2 C2 A3 B3 C3 A4 B4 C4

Fig. 6 Mean forces during stationary chip removal in tangential, radial and axial direction relative to the tapping tool, based on experimental results

Concerning the axial force, the chip shape must be considered more closely. Generally, in blind hole tapping, the negative axial forces can be explained by the angle of the helical flute of the tap. However, the contact of the tooth flanks with the workpiece can partly compensate the axial forces. Since there is no contact between the lower tooth flank and the workpiece for teeth B1-A2, there is no support to compensate negative forces (see Fig. 7). From tooth B2 onwards, there is also contact between the tooth and the lower thread flank, adding not measurable contact forces to the equation. From tooth B3 onwards, the measured axial forces change their sign. It can be assumed that the tooth flanks already compensate the chip induced axial forces to a large extent and the measured axial forces are mainly affected by the friction against the feed direction. 


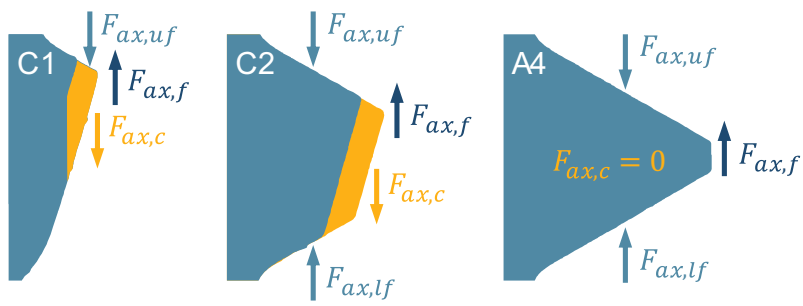

Fig. 7 Axial force on the tooth: Axial forces on the upper tooth flank $F_{a x, u f}$, axial forces on the lower tooth flank $F_{a x, l f}$, chip induced axial forces $F_{a x, c}$ and axial friction forces $F_{a x, f}$

\subsection{Force modelling}

During tapping, the resulting radial force, combining all force components in the $x-y-p l a n e$, causes tool deflection. According to the mechanistic approach these process forces can be described as the product of the specific cutting force $K$ and the cross-section area of the undeformed chip $A$ [3]. For each individual tooth the tangential force $F_{t a n, i}$ and the radial force $F_{r a d, i}$ can be described as follows:

$F_{\text {tan }, i}=K_{\text {tan }} \cdot A_{i}$

$F_{r a d, i}=K_{r a d} \cdot A_{i}$

According to Ehmann [5] however, the specific process forces are generally not constant. Therefore, the model includes the influences of the undeformed chip thickness $h$ and cutting speed $v_{c}$. Following Dogra et al. [1], the specific forces can be described using the following equations.

$$
\begin{aligned}
\log \left(K_{\text {tan }}\right)= & a_{0}+a_{1} \log (h)+a_{2} \log \left(v_{c}\right) \\
& +a_{3} \log (h) \log \left(v_{c}\right)
\end{aligned}
$$

$$
\begin{aligned}
\log \left(K_{r a d}\right)= & a_{0}+a_{1} \log (h)+a_{2} \log \left(v_{c}\right) \\
& +a_{3} \log (h) \log \left(v_{c}\right)
\end{aligned}
$$

In the calculation of the specific forces, large deviations can be seen for teeth with small undeformed chip cross-section areas such as B1, since measurement uncertainty in the force signals is amplified when divided by a small value. Therefore, only the teeth $\mathrm{C} 1-\mathrm{C} 3$, having a sufficiently large crosssection area of the undeformed chip, are considered for the calibration of the force model. The coefficients shown in Table 3 are estimated using a multivariate regression analysis with least squares method.

The specific tangential and radial forces in relation to the undeformed chip thickness $h$ and the cutting speed $v_{c}$ are shown in Fig. 8. For large undeformed chip thicknesses, the cutting speed has a small effect on the specific
Table 3 Coefficients for the specific forces in the cutting section of the tap

\begin{tabular}{lll}
\hline Coefficient & $K_{\text {tan }}$ & $K_{\text {rad }}$ \\
\hline$a_{0}$ & 4.1171 & 0.5453 \\
$a_{1}$ & -2.0128 & -3.3692 \\
$a_{2}$ & 1.0054 & 1.682 \\
$a_{3}$ & 0.50999 & 0.82057 \\
Adj. $R^{2}$ & 0.893 & 0.844 \\
\hline
\end{tabular}

forces in the considered parameter range. The influence however increases with decreasing values of the undeformed chip thickness $h$. It can be assumed, that this is due to the relatively higher share of contact and friction forces.

Since no more chips are removed in the guiding section of the tool, no specific force can be calculated here. Therefore, the specific edge forces $K_{E}$ are calculated according to Puzović [12] based on the measured edge forces $F_{E}$ and the geometrically determined contact length $L$.
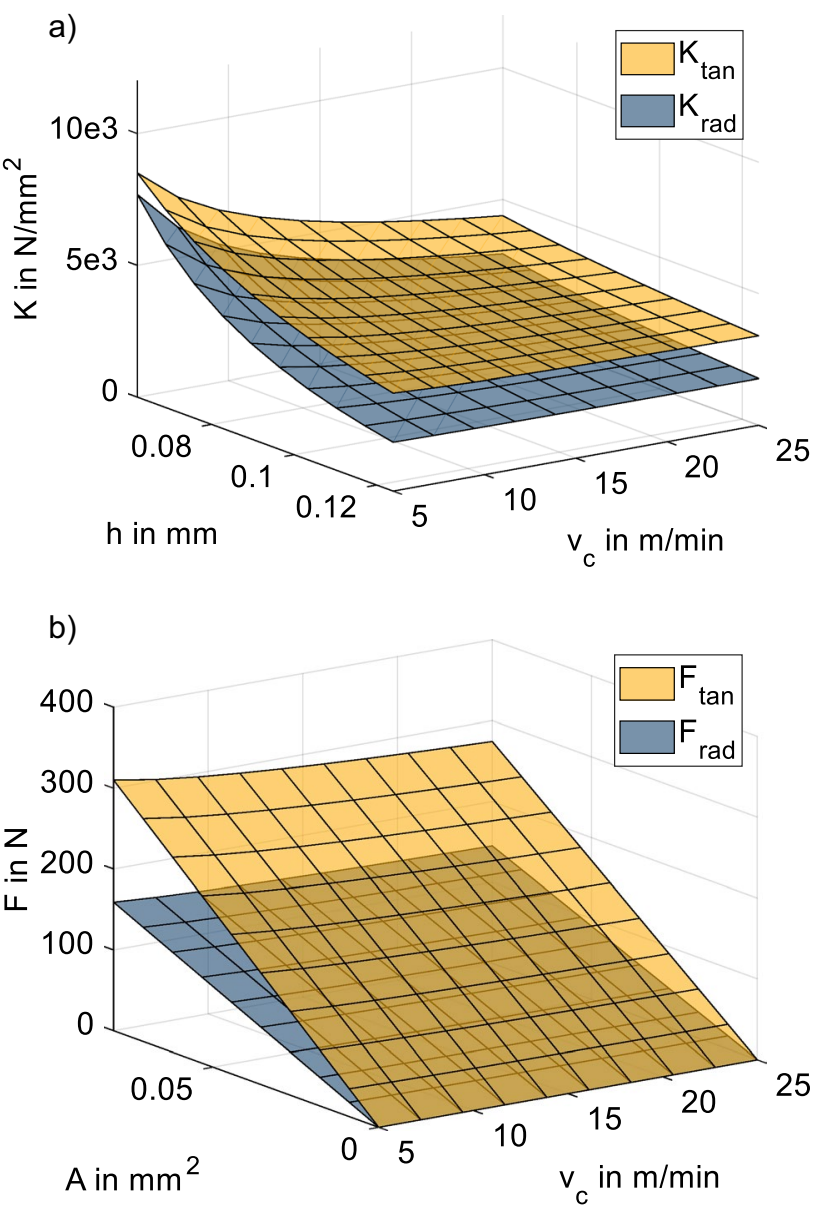

Fig. 8 Modelling results: a specific tangential and radial forces in relation to the thickness of the undeformed chip $h$ and the cutting speed $v_{c}$, b process forces in relation to the cross-section area of the undeformed chip $A$ and the cutting speed $v_{c}$ for $h=0.12 \mathrm{~mm}$ 
$F_{E}=K_{E} \cdot L$

The thus calculated specific edge forces in radial direction can be related to the cutting speed $v_{c}$. Using linear regression the relation can be described as:

$K_{E, r a d}=32.599-0.65395 \cdot v_{c}$

With an adjusted coefficient of determination of $R^{2}=0.928$, the regression shows a good fit for $K_{E, \text { rad }}$. This shows a decrease in radial edge forces with increasing cutting speed for the tested tooth of the guiding section. For $K_{E, t a n}$ however, no significant correlation to the cutting speed can be seen. The specific tangential edge force for the measured teeth of the guiding section can therefore be seen as constant.

\subsection{Model validation}

The empirical cutting force model is validated by implementing it within a simulation model, as shown in [33], based on the mechanistic framework and comparing the resulting torque to experimental data. In the simulation the tool-workpiece intersection is calculated with a chip crosssection model [6] using the extracted 2D element set model from Sect. 4.1 as input. The tapping tests are, performed on a GROB G350 machining center, using a tool holder with minimum length compensation and internal cooling with an emulsion with $8.8 \%$ oil content. The pre-drilled bore is a blind hole with a measured diameter of $6.82 \mathrm{~mm}$. Within the simulation, the torque is calculated by summing up the products of the tangential forces and the radius of the undeformed chip centerpoint. The measured and simulated torque signals are plotted in Fig. 9, showing a good agreement. The increase in the measured signal at greater immersion depth can be attributed to chip removal against the feed direction during blind hole tapping. However, this effect is not represented in the force model, which explains the deviation at this point.

\section{Conclusion and outlook}

In this paper, a methodology for measuring and modelling of process forces during tapping is presented. The basis is an experimental analogy process to measure the forces on each tooth of a tapping tool separately without the need to modify the tool geometry. During the analogy process, forces in tangential, radial and axial direction can be measured for all teeth of the cutting section of the tool. This allows a deeper insight in the load distribution, especially regarding the radial forces that are not directly measurable in the real tapping process, but can lead to a lateral deflection of the tool. In addition the forces on the

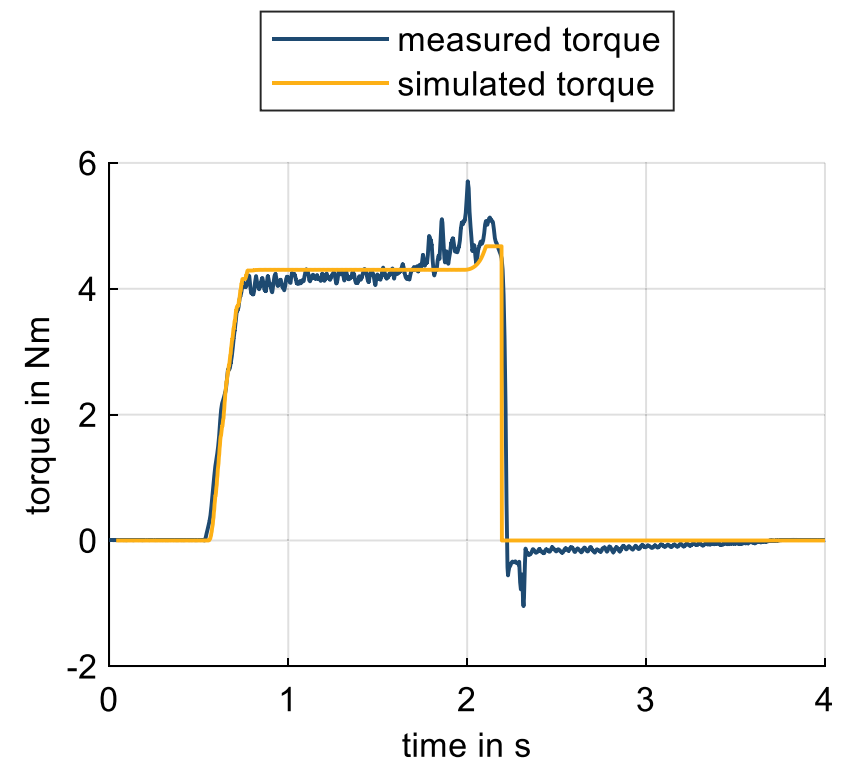

Fig. 9 Comparison of measured and simulated torque for M8x1.25 blind hole tapping $\left(v_{c}=15 \mathrm{~m} / \mathrm{min}, d_{k}=6.82 \mathrm{~mm}\right)$ in $42 \mathrm{CrMo} 4$

first teeth of the guiding section are measured to get an insight on the occurring edge forces. It could be shown that radial forces on the first teeth of the guiding section decrease with increasing cutting speed.

To compare the measured force signals with the real tooth geometry, a 2D element set model is extracted from the optically measured geometry of the tap used in the experiments. This allows to also take manufacturing uncertainty into account. With the extracted tool model, the chip sizes, such as the cross-section area of the undeformed chip, are determined. Combining the real tool geometry and calculated chip sizes with the measured forces a force model is set up, taking the chip thickness and cutting speed into account. It could be shown, that the influence of the undeformed chip thickness increases with decreasing cutting speed. The model is validated by comparing simulated and measured torque signals and shows a good accordance.

The empirically determined force model is crucial for explaining tool displacement based on the mechanistic approach. This can be used to simulate the effects of uncertainty like axis misalignment, tool runout, a slope pilot bore or synchronization errors on the tapping process and the thread geometry with little computing time and thus support the knowledge-based tool and process design. In this context, further work should also focus the complex contact conditions to describe the interaction between the tap and the already cut thread to gain deeper knowledge of the tapping process.

Acknowledgements The authors would like to thank the German Research Foundation, DFG, for funding this research within the 
Collaborative Research Center SFB 805 "Control of Uncertainties in Load-Carrying Structures in Mechanical Engineering".

Funding Open Access funding enabled and organized by Projekt DEAL.

Open Access This article is licensed under a Creative Commons Attribution 4.0 International License, which permits use, sharing, adaptation, distribution and reproduction in any medium or format, as long as you give appropriate credit to the original author(s) and the source, provide a link to the Creative Commons licence, and indicate if changes were made. The images or other third party material in this article are included in the article's Creative Commons licence, unless indicated otherwise in a credit line to the material. If material is not included in the article's Creative Commons licence and your intended use is not permitted by statutory regulation or exceeds the permitted use, you will need to obtain permission directly from the copyright holder. To view a copy of this licence, visit http://creativecommons.org/licenses/by/4.0/.

\section{References}

1. Dogra APS, Kapoor SG, DeVor RE (2002) Mechanistic model for tapping process with emphasis on process faults and hole geometry. J Manuf Sci Eng 124:18-25. https://doi.org/10.1115/1.14302 37

2. Patel HJ, Patel BP, Patel SM (2012) A review on thread tapping operation and parametric study. Int J Eng Res Appl 2(3):109-113

3. Koenigsberger F, Sabberwal A (1961) An investigation into the cutting force pulsations during milling operations. Int J Mach Tool Des Res 1(1-2):15-33. https://doi.org/10.1016/00207357(61)90041-5

4. Kapoor SG, DeVor RE, Zhu R, Gajjela R, Parakkal G, Smithey D (1998) Development of mechanistic models for the prediction of machining performance: model building methodology. Mach Sci Technol 2(2):213-238

5. Ehmann KF, Kapoor SG, DeVor RE, Lazoglu I (1997) Machining process modeling - a review. J Manuf Sci Eng 119:655-663

6. Abele E, Geßner F (2018) Spanungsquerschnittmodell zum Gewindebohren: Modellierung der Auswirkung von Unsicherheit auf den Spanungsquerschnitt beim Gewindebohren. Werkstattstechnik Online 108(1/2):2-6

7. Dogra APS, DeVor RE, Kapoor SG (2002) Analysis of feed errors in tapping by contact stress model. J Manuf Sci Eng 124:248-257. https://doi.org/10.1115/1.1454107

8. Mezentsev OA, Zhu R, DeVor RE, Kapoor SG, Kline WA (2002) Use of radial forces for fault detection in tapping. Int $\mathrm{J}$ Mach Tools Manuf 42:479-488. https://doi.org/10.1016/S0890 -6955(01)00139-0

9. Cao T, Sutherland JW (2002) Investigation of thread tapping load characteristics through mechanistics modeling and experimentation. Int J Mach Tools Manuf 42(14):1527-1538. https://doi. org/10.1016/S0890-6955(02)00108-6

10. Armarego EJA (2000) The unified-generalized mechanics of cutting approach - a step towards a house of predictive performance models for machining operations. Mach Sci Technol 4(3):319_ 362. https://doi.org/10.1080/10940340008945715

11. Armarego EJA, Chen MN (2002) Predictive cutting models for the forces and torque in machine tapping with straight flute taps. CIRP Ann Manuf Technol 51(1):75-78. https://doi.org/10.1016/ S0007-8506(07)61469-3

12. Puzović R, Kokotović B (2006) Prediction of thrust force and torque in tapping operations using computers simulation. FME Trans 34:1-5
13. Chen NM, Smith AJR (2011) Modelling of straight-flute machine tapping. J Eng Manuf 225(9):1552-1567. https://doi. org/10.1177/0954405411408650

14. Wan M, Ma YC, Feng J, Zhang WH (2017) Mechanics of tapping process with emphasis on measurement of feed error and estimation of its induced indentation forces. Int J Mach Tools Manuf 114:8-20. https://doi.org/10.1016/j.ijmachtools.2016.12.003

15. Popović M, Stoić A, Tanović L (2016) Prediction of tapping forces and torque for $16 \mathrm{MnCr} 5$ alloyed steel. Tehnicki vjesnik (Technical Gazette) 23(3):873-879. https://doi.org/10.17559/TV-20150 618074143

16. Bölling C, Kuhne M, Abele E (2017) Modeling of process forces with consideration of tool wear for machining of sintered steel alloy for application to valve seat in acombustion engine. Prod Eng 11(4-5):477-485. https://doi.org/10.1007/s11740-017-0759-y

17. Oezkaya E, Biermann D (2017) Segmented and mathematical model for 3D FEM tapping simulation to predict the relative torque before tool production. Int J Mech Sci 128-129:695-708. https://doi.org/10.1016/j.ijmecsci.2017.04.011

18. Oezkaya E, Biermann D (2018) Development of a geometrical torque prediction method (GTPM) to automatically determine the relative torque for different tapping tools and diameters. Int $\mathrm{J}$ Adv Manuf Technol 97:1465-1479. https://doi.org/10.1007/s0017 0-018-2037-3

19. Pereira IC, Da Silva MB (2017) Study of the internal thread process with cut and form taps according to secondary characteristics of the process. Int J Adv Manuf Technol 93(5-8):2357-2368. https://doi.org/10.1007/s00170-017-0573-x

20. Pereira IC, Vianello PI, Boing D, Guimarães G, Da Silva MB (2020) An approach to torque and temperature thread by thread on tapping. Int J Adv Manuf Technol 29(1):4891-4901. https:// doi.org/10.1007/s00170-020-04986-8

21. DIN 2197-1:2015-03 (2015) Screwing taps-part 1: technical delivery conditions for ground high-speed steel taps. Beuth, Berlin

22. Steininger A, Siller A, Bleicher F (2015) Investigations regarding process stability aspects in thread tapping Al-Si alloys. Procedia Eng 100:1124-1132. https://doi.org/10.1016/j.proen g.2015.01.475

23. DIN 371:2016-01 (2016) Machine taps with reinforced shank for coarse pitch metric ISO-threads M1 to M10 and fine pitch metric ISO-threads $\mathrm{M} 1 \times 0.2$ to $\mathrm{M} 10 \times 1.25$. Beuth, Berlin

24. DIN 6581:1985-10 (1985) Terminology of chip removing; reference systems and angles on the cutting part of the tool. Beuth, Berlin

25. Zabel A (2010) Prozesssimulation in der Zerspanung: Modellierung von Dreh- und Fräsprozessen, 2nd edn. Vulkan, Essen

26. Paucksch E, Holsten S, Linß M, Tikal F (2008) Zerspantechnik: Prozesse, Werkzeuge. Technologien. Vieweg + Teubner, Wiesbaden

27. Ahn JH, Lee DJ, Kim SH, Kim HY, Cho KK (2003) Effects of synchronizing errors on cutting performance in the ultra-highspeed tapping. CIRP Ann Manuf Technol 52(1):53-56. https:// doi.org/10.1016/S0007-8506(07)60529-0

28. Holsten S (2005) FEM-unterstützte Parameterstudie des Innengewindefertigungsverfahrens Gewindefurchen. Dissertation, Universität Kassel

29. Bienemann R (2009) Evaluation der Schneidkantenbelastung beim Gewindebohren schwer zerspanbarer Werkstoffe. Dissertation, Universität Kassel

30. Pereira IC, Da Silva MB, Da Cunha DF, Sales WF (2015) Analysis of tapping process in three types of cast iron. Int $\mathrm{J}$ Adv Manuf Technol 82(5-8):1041-1048. https://doi.org/10.1007/s0017 $0-015-7430-6$

31. DIN 13-28:1975-09 (1975) ISO Metric threads with diameters from 1 up to $250 \mathrm{~mm}$; root sections-tensile stress areas-lead angles. Beuth, Berlin 
32. DIN 336:2003-07 (2003) Diameters of drills for minor diameters of tapped threads. Beuth, Berlin

33. Boelling C, Abele E (2018) Simulation of multi-stage fine machining processes at the example of valve guide and valve seat. AMM 885:255-266. https://doi.org/10.4028/www.scientific.net/ AMM.885.255
Publisher's Note Springer Nature remains neutral with regard to jurisdictional claims in published maps and institutional affiliations. 